\title{
Self-Healing Hybrid Hydro/PV System with Power Quality Improvement and Output Optimization
}

\author{
Rakshith P \\ Asisstant Professor \\ Dept. of EEE, VVCE \\ Mysuru, India
}

\author{
Preethi N D \\ Dept. of EEE, VVCE \\ Mysuru, India
}

\author{
Yuvaraj A R \\ Dept. of EEE, VVCE \\ Mysuru, India
}

\author{
Nisarga \\ Dept. of EEE, VVCE \\ Mysuru, India
}

\author{
Gagan Simha R \\ Dept. of EEE, VVCE \\ Mysuru, India
}

\begin{abstract}
The growing demand on fossil fuels has made it necessary to use renewable energy resource as a substitute energy source for generation of electrical energy. The hybridization of the PV system with the hydro power generating system ensures the continuity in supply and thus the generation is made more reliable. Due to the continuously varying environmental conditions the output of such systems keeps on changing. In this paper a self-healing hybrid hydro/PV system is designed which is capable of supplying the maximum possible power irrespective of variable irradiance and temperature in PV system and variable prime mover speed in hydro system. The PV system is used for supplying loads when sufficient irradiation is available and hydro system is used in the absence of PV generation. The output optimization is obtained by incorporation of incremental conductance method of Maximum Power Point Tracking. The self-healing model is also designed to address the power quality issues arising due to voltage sags that are caused as a result of three-phase faults in the system. A power quality compensation scheme is used to fulfill the above mentioned objective. A Dynamic Voltage Restorer is used for balancing the voltage and to maintain the voltage profile of the power system. The demonstration of the behavior of the designed model is carried on using Matlab/Simulink software.
\end{abstract}

Keywords- Hybrid, Hydro/PV, Maximum Power Point Tracking (MPPT), Cascaded H-Bridge Multilevel Inverter (CHB), Dynamic Voltage Restorer

(DVR),Incremental Conductance (IncCond), Total Harmonic Distortion (THD).

\section{INTRODUCTION}

The use of renewable energy resources for power generation has become a matter of extreme significance because of the burden on the fossil fuels. The major obstacles to a power system are its reliability and efficiency. In order to overcome these obstacles the power generation should be made continuous and this can be done more efficiently by combining renewable energy resources with conventional energy generation systems. A hybrid hydro/ PV system is one such combination of energy generation systems. In this hybrid system the PV supplies the power when sufficient solar irradiation is available and hydro generates the power in absence of PV. The varying environmental conditions have a direct impact on the output power generation. Therefore, in order to maintain a constant power output irrespective of the fluctuations in the environment a MPPT control scheme is used. This control scheme uses incremental conductance algorithm of MPPT to operate the system at its maximum power point resulting in highest possible power at the output of the hybrid system. The system is also employed with a power quality compensation scheme. This scheme compensates the disturbances caused to the power quality by the voltage sags occurring as a result of three phase faults. The DVR used in this scheme does the work of voltage injection to maintain the voltage profile and thereby helps in retaining the power quality.

\section{METHODOLOGY}

\section{A. System Architecture}

Fig.1. represents the schematic of the proposed system.

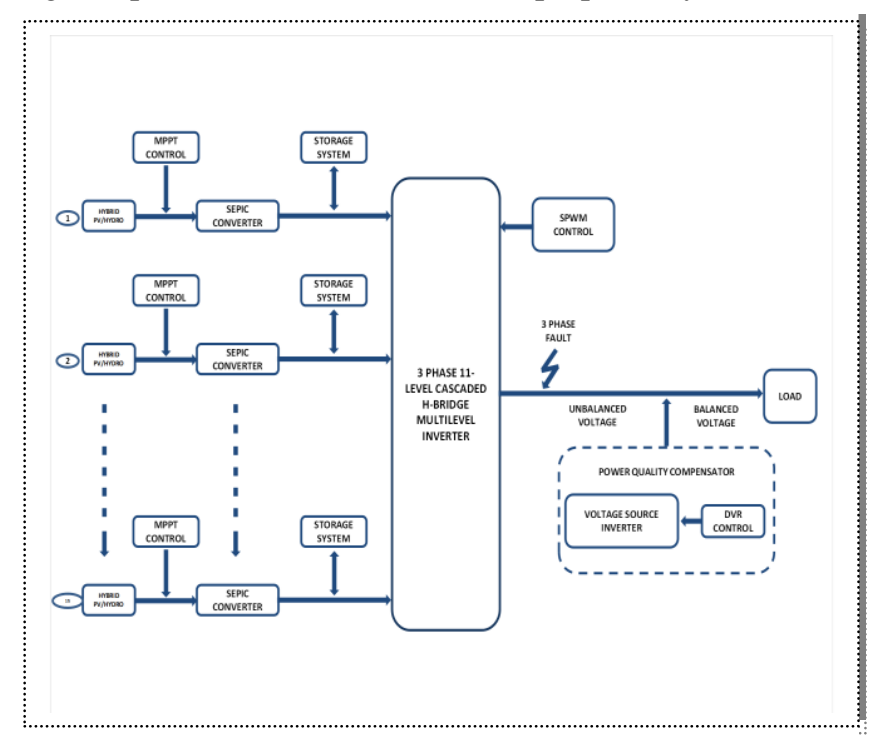

Fig.1 Representation of the Proposed System Architecture

The architecture of the proposed system is as shown in the Fig.1. A combination of hydro and PV system is used as the 
input source for power generation.The tracking of the output voltage takes place in the MPPT control scheme ensuring the operation of the system at its maximum power point. The MPPT control scheme using incremental conductance algorithm adjusts the duty cycle of the single ended primary inductor conductor (SEPIC) converter to maintain the tracked ouput at a constant value. The tracked and boosted output voltage is $500 \mathrm{~V}$. The energy is stored in the storage systems during excess power generation else it is fed to the inverter. In the absence of the PV generation the batteries feed the inverter thus catering the loads for short durations. The inverter used here is 3- $\Phi, 11$-level Cascaded H-Bridge Multilevel Inverter. Every DC link of the inverter is fed by individual hybrid system. The input is converted from DC to $4 \mathrm{kV}$ AC line volatge. Sine Pulse Width Modulation technique is used to control the gating signals given to the inverter. An artificial 3$\Phi$ fault is created which causes voltage sag in the load voltage. The DVR senses the voltage disturbance and injects suitable voltage to maintain the voltage profile. Thus the power quality issues arising due to voltage sag is compensated by the DVR equipped in the power quality compensation scheme.

\section{B. Modelling of Hybrid System}

A solar PV is used in combination with a hydro system to form the hybrid system. Photovoltaic (PV) is the transformation of light energy into electricity. The PV uses semiconducting materials that exhibit the photovoltaic effect. The PV system comprises of solar panels within which a number of PV cells are employed that are capable of generating electrical power. PV systems operate best with direct sunlight. About 10-25\% of the power output is lost if a suitable tracking system is not employed. Environmental variations and other obstructions in the atmosphere also lead to diminished power output. In this paper the environmental variations taken into consideration are temperature and irradiance [1].

Hydro systems with variable speed have significant attention in renewable energy field due to its overall efficiency. When used with a MPPT control scheme it ensures high energy efficiency when operated in free water flows that varies the prime mover speed continuously [2].

The specifications of the solar panel are mentioned below

Sun Power SPR-305-WHT, No. of cells/ module $=96$ cells, Input Temperature $=25^{\circ} \mathrm{C}$, Input Irradiance $=1000 \mathrm{~W} / \mathrm{m}^{2}$, Open circuit voltage $(\mathrm{Voc})=62.4 \mathrm{~V}, \mathrm{Vmp}=54.7 \mathrm{~V}$, Short circuit current $(\mathrm{Isc})=5.96 \mathrm{~A}, \mathrm{Imp}=5.58 \mathrm{~A}$ [4]

No. of cells per module, per string $=\frac{\text { Desired output voltage }}{\text { Voltage at MPP }}$

$=\frac{275 \mathrm{~V}}{57.4 \mathrm{~V}}=5$

- Equation 1

No. of parallel Strings $=\frac{\text { Output Current }}{\text { Current at MPP }}$

$=\frac{\text { (Desired Power Output/Desired Output voltage) }}{}$

Current at MPP

$=\frac{25 \mathrm{~kW} / 275 \mathrm{~V}}{5.58 \mathrm{~A}}=\frac{66}{4}$

- Equation 2

\section{SEPIC Converter}

The circuit used for the transformation of fixed DC voltage to variable DC voltage is a DC/DC converter. The ouput voltage of the inverter can be equal to the input or it can be greater than or lessser than the input voltage. SEPIC is used widely for better performance for conversion of voltage. In applications where output is not according to the input it is better to use convert that can decrease or increase the voltage[14]. Buck-boost converter is expensive because of the remedy used to overcome the effect of high harmonic content caused by the large of large amount of input current ripple. Also, the output voltage is inverted. These drawbacks are overcome by Cuk converter but it will create electrical stress which may lead to componenet failure or excessive heating. Thus SEPIC converter capable of overcoming both the above mentioned drawbacks is used. The output of the converter can be adjusted by adjusting the duty cycle. The duty cycle adjustment is carried on by Incremental Conductance tracking algorithm [6].

\section{Optimization by Incremental Conductance Method}

Incremental conductance of MPPT is used as control technique for achieving the optimization of power output. The fluctuations in the environmental conditions such as varying irradiance and varying temperature in PV systems and variable prime mover speed in hydro systems results in variations in the output power being tapped from the system. Thus incremental conductance algorithm of MPPT is incorporated to obtain a constant output irrespective of the changes impacting the power output. The incremental conductance method is chosen because of its capability of operating stably even under fast varying environmental conditions [5].

\section{E. Cascaded H-Bridge Multilevel Inverter}

The voltage inversion is achieved by making use of a multilevel inverter in particular a cascaded h-bridge multilevel inverter. A 3- $\Phi$, 11-level cascaded h-bridge multilevel inverter is used. Each phase has 5 DC links for which individual hybrid system acts as input. There are totally 15 DC links in the 3- $\Phi$ inverter which are supplied by separate hybrid systems with exclusive MPPT control scheme [10]. The gating signals to the switches of the inverter are controlled by sine pulse width modulation technique. Using this technique 11 levels of voltages are obtained from the inverter by comparing a single sine wave with ten different triangular reference signals. The gating pulses generated are used for controlling the switching action of the inverter [7]. By increasing the number of levels the THD goes on decreasing and also the implementation of SPWM results in reduced THD.

\section{F. Power Quality Compensation}

The power quality compensation scheme consists of a DVR and a voltage source inverter. The power quality compensation scheme mainly aims at resolving the power quality issue that arises due to the voltage sags occurring in the system under different fault conditions. The DVR detects the voltage sags. The magnitude of the voltage sag is compared with the reference voltage or desired voltage. The difference in the voltage magnitude is injected by the voltage source inverter to maintain the necessary voltage. Thus despite the faults 
occurring in the system the system are capable of restoring the voltage to nominal values with the help of the power quality compensation scheme. Since the unbalanced voltage is balanced before supplying it to the load it ensures reliability of supply[12] [13].

\section{MATLAB SIMULATION}

Simulink is a visual programming interface for modeling, simulation and analyzing the systems. The software based demonstration of the desired PV system is carried on in Matlab/Simulink software. When solar irradiation is 1000 Watt $/ \mathrm{m}^{2}$ and the temperature is $25^{\circ}$ Celsius the PV array can deliver a maximum power of $25 \mathrm{~kW}$. The PV voltage is boosted from $300 \mathrm{~V}$ DC to $500 \mathrm{~V}$ DC by the SEPIC converter. Switching of duty cycle due to different environmental conditions is optimized by incremental conductance MPPT control scheme employed in the designed model. The Cascaded H-Bridge inverter inverts the output voltage obtained from SEPIC converters to $1466 \mathrm{~V}$ AC in each phase. The inverted output is then stepped down to $440 \mathrm{~V}$ AC by a step down transformer. CHB inverter renders DC links that can be connected to each PV array with an exclusive MPPT control scheme. The power quality related issues such as sag and swell in voltage are overcome by the DVR control scheme during faulty conditions. Therefore, the quality of power in the system remains intact. The simulated model of the controlled PV system is depicted in Fig. 2.

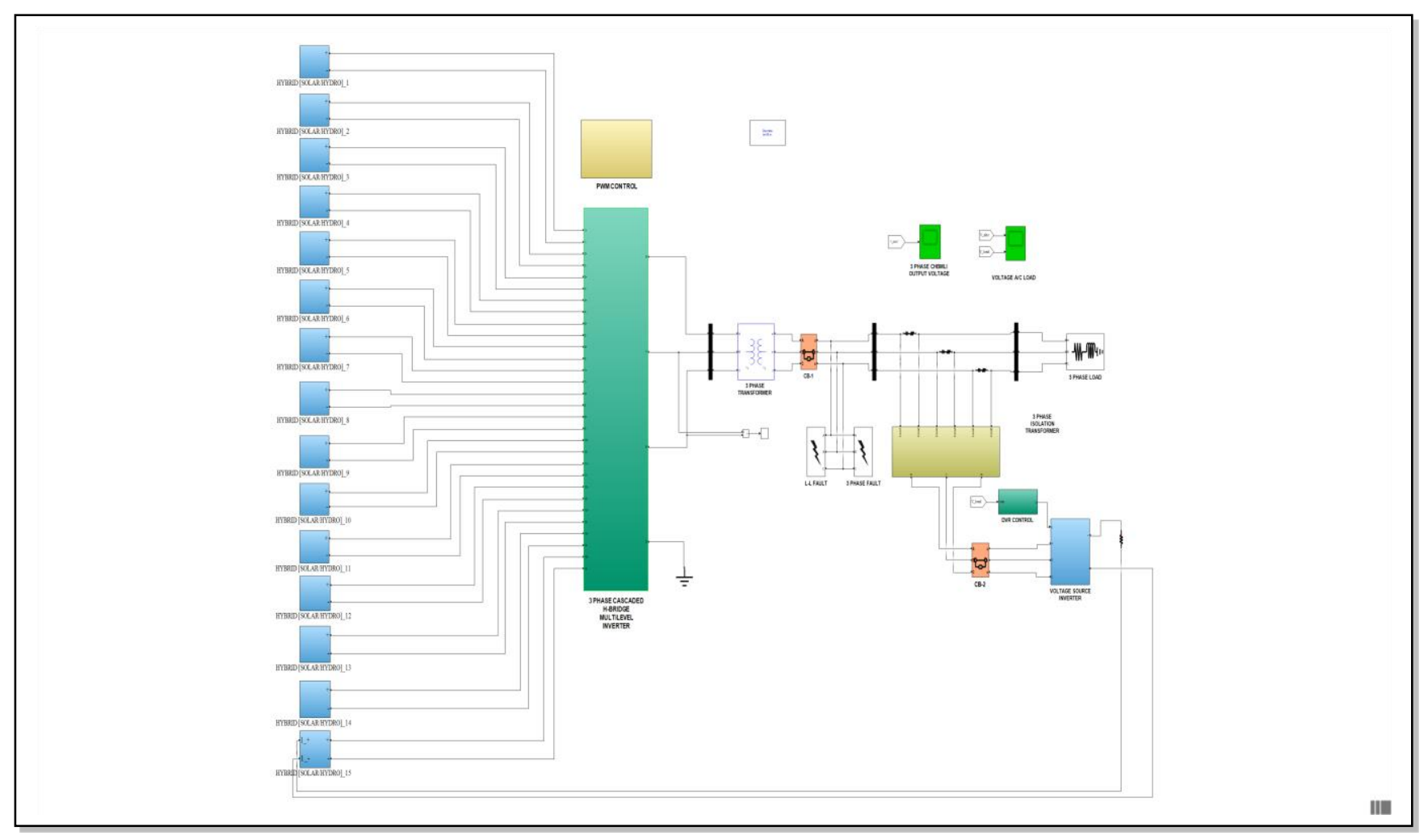

Fig.2 Simulink Model of the Hybrid Hydro PV System with Proposed Capabilities.

\section{RESULTS AND DISCUSSION}

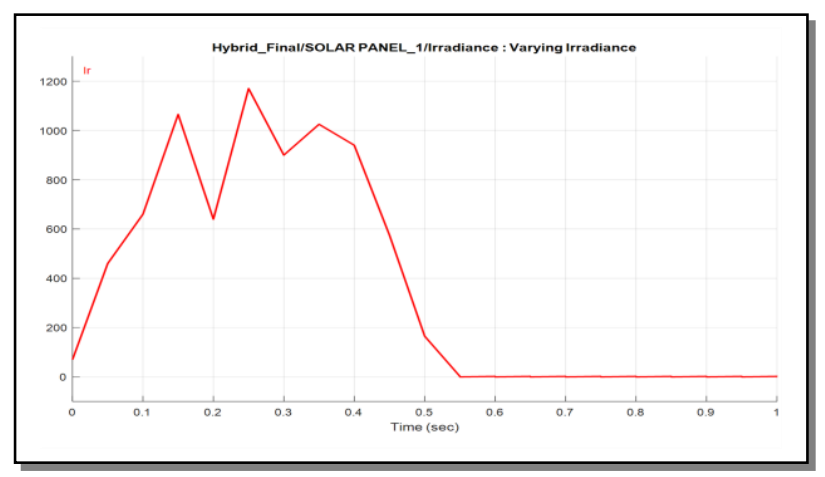

Fig.3 Varying Solar Irradiance to PV System in $\mathrm{W} / \mathrm{m}^{2}$

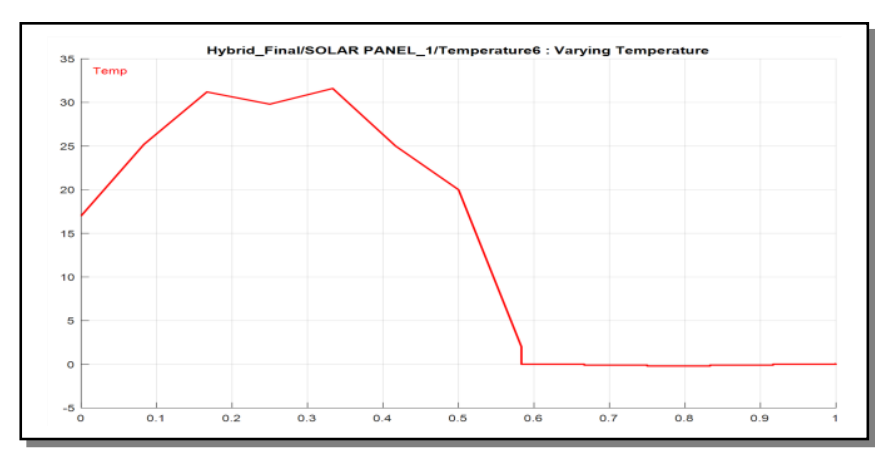

Fig.4 Varying Temperature Input to PV System in ${ }^{\circ} \mathrm{C}$ 
Fig. 3 shows the irradiance given to the PV sytem which is not constant throughout the day. The irradiance is varying continuously and the varying irradiance is given as one of the inputs to the PV system.. Fig.4 represents the varying temperature input given to the Pv system. Since the Pv system is simulated for 0.5 seconds are variations given for the PV system is also for 0.5 seconds.

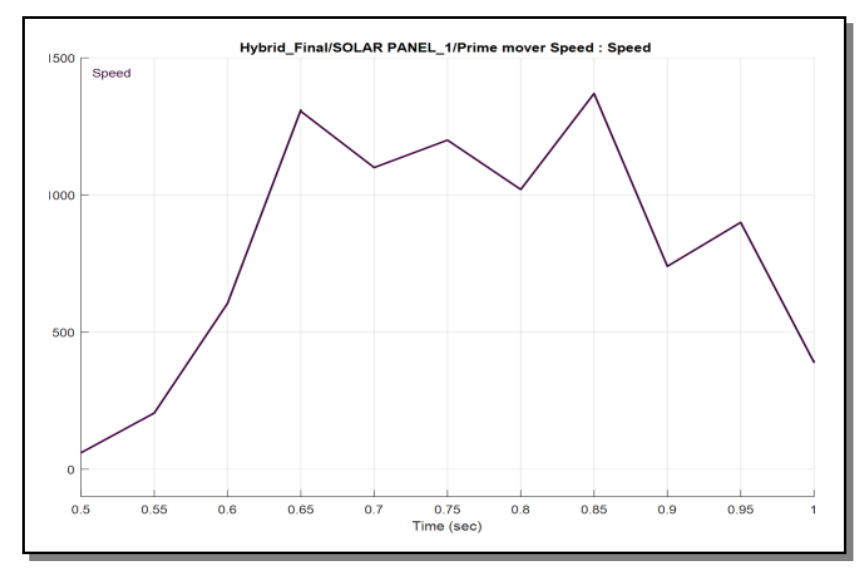

Fig.5 Varying Prime Mover Speed Given As Input To The Hydro System

The hydro system is fed with the varying speed flow of water with prime mover speed variations as input. Since the hydro sytem is simulated from $0.5-1$ seconds the variations are considered during this period only as shown in Fig.5.

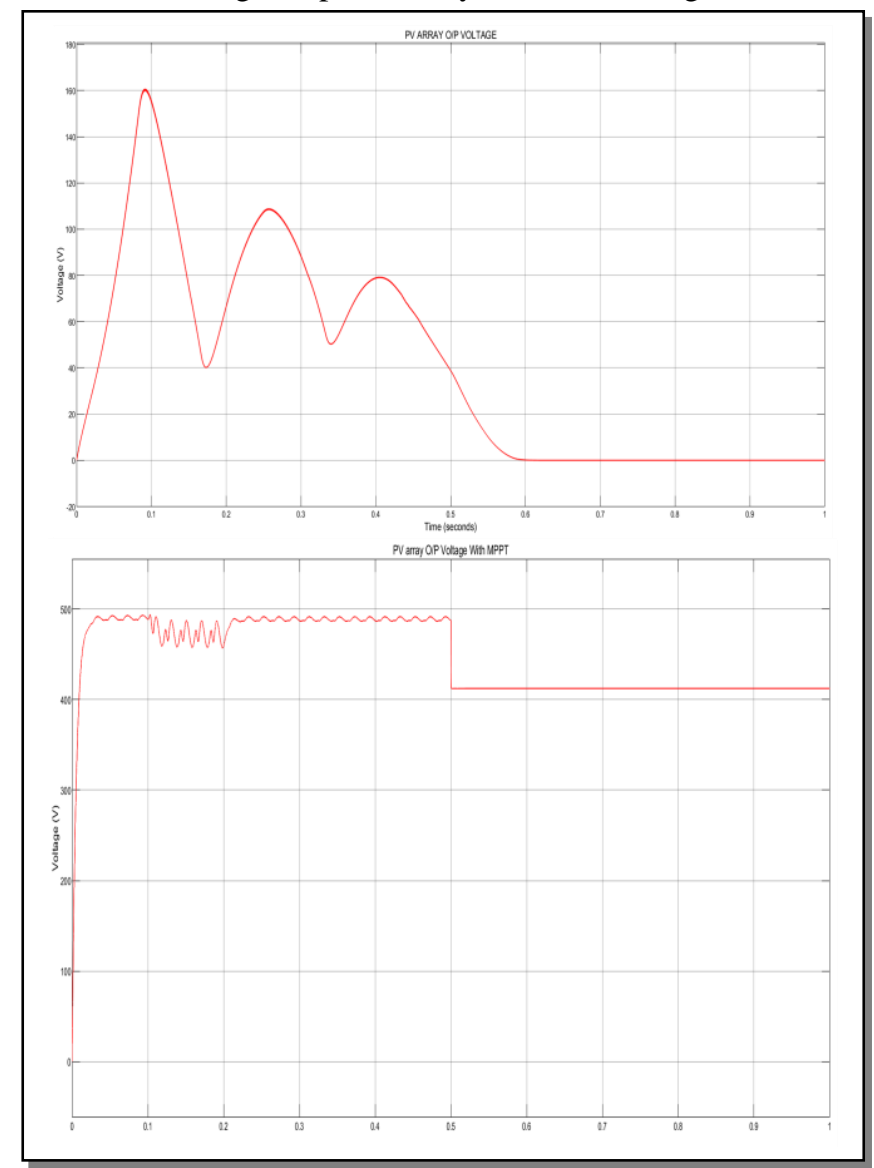

Fig.6 PV Array Output Voltage With and Without MPPT Control Scheme.
The output of the PV system with and without MPPT control scheme is demonstrated in the Fig.6. The varying irradiance and temperature causes fluctuations in the output. The fluctuating output voltage is made constant by the MPPT control scheme. The tracked voltage of $300 \mathrm{~V}$ is boosted to $500 \mathrm{~V}$ by SEPIC and constant output is obtained which can be seen in the Fig.6.

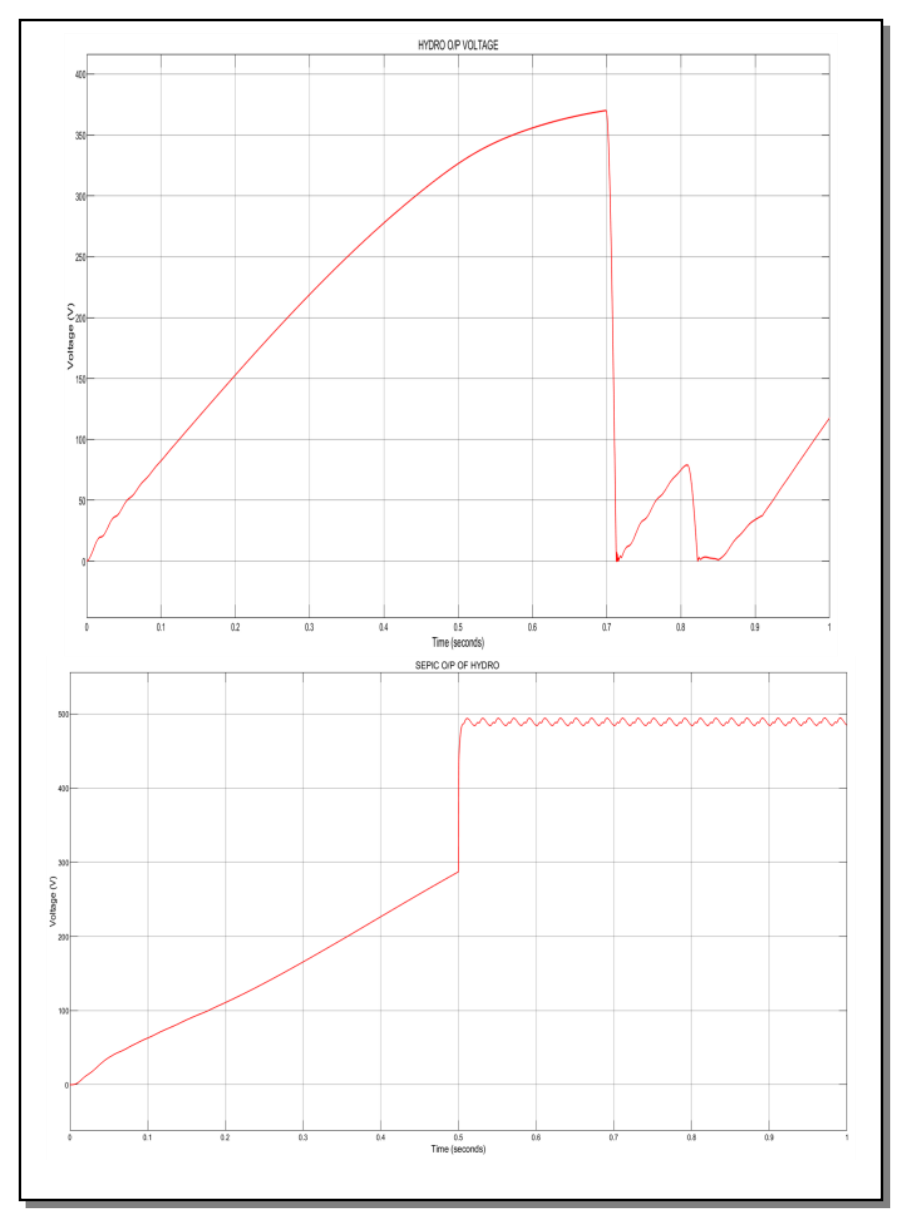

Fig.7 Hydro System Output Voltage With and Without MPPT Control Scheme.

The output of the hydro system with and without MPPT control scheme is demonstrated in the Fig.7. The varying prime mover speed causes fluctuations in the output. The fluctuating output voltage is made constant by the MPPT control scheme. The tracked voltage of $300 \mathrm{~V}$ is boosted to $500 \mathrm{~V}$ by SEPIC and constant output is obtained which can be seen in the Fig.7.

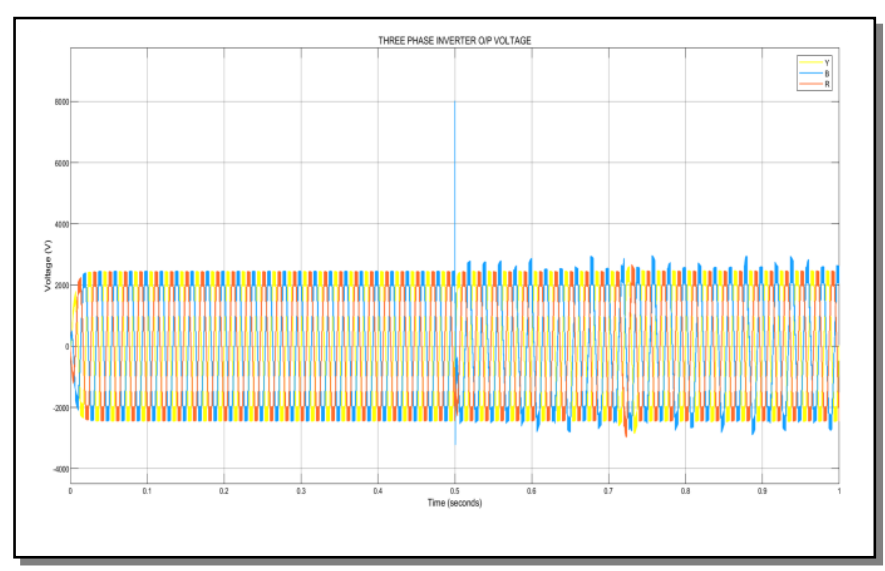

Fig.8 Three Phase Inverter Output Voltage under Normal Condition. 
The Fig. 8 demonstrates the three phase output of the cascaded h-bridge multilevel inverter. The voltage obtained at the output of the inverter is $2 \mathrm{kV}$ phase voltage.

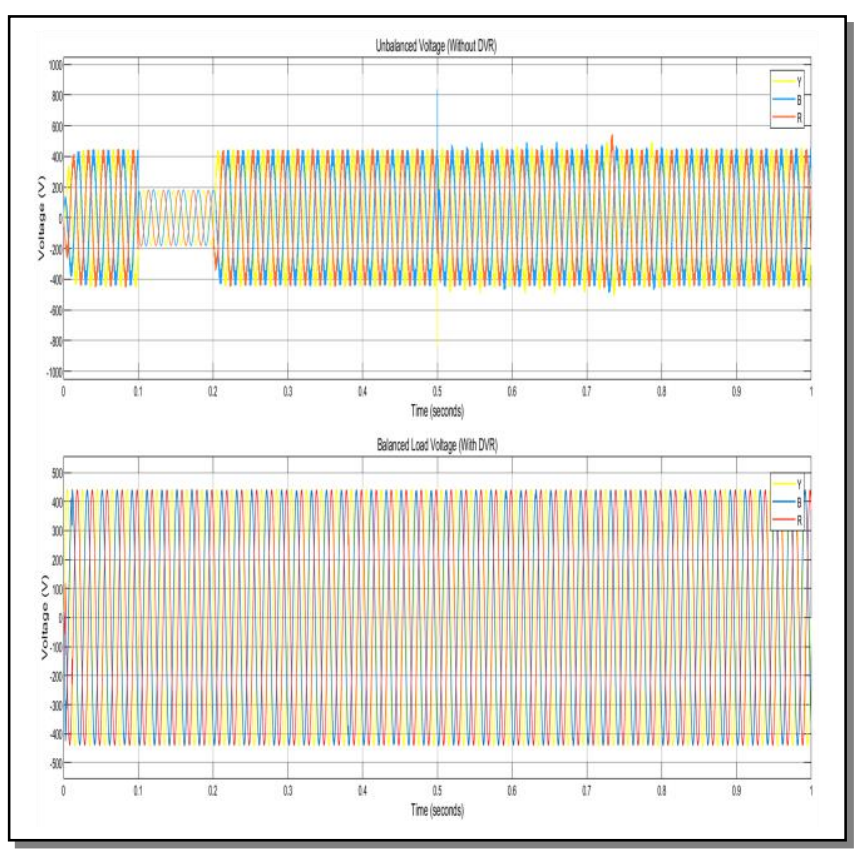

Fig.9 Load Voltage With and Without DVR.

Fig.9 shows the load voltage with and without DVR. An artificial three phase fault is created during 0.1-0.2 second as shown in the figure. During the fault the voltage sags and magnitude of the load voltage is nearly $200 \mathrm{~V}$ which is undesirable. The DVR incorporated compensates the voltage sag by making the load voltage magnitude equal to $440 \mathrm{~V}$ which is shown in Fig.9. The unbalance in the voltage is balanced and then supplied to the load to ensure reliable operation of the hybrid system.

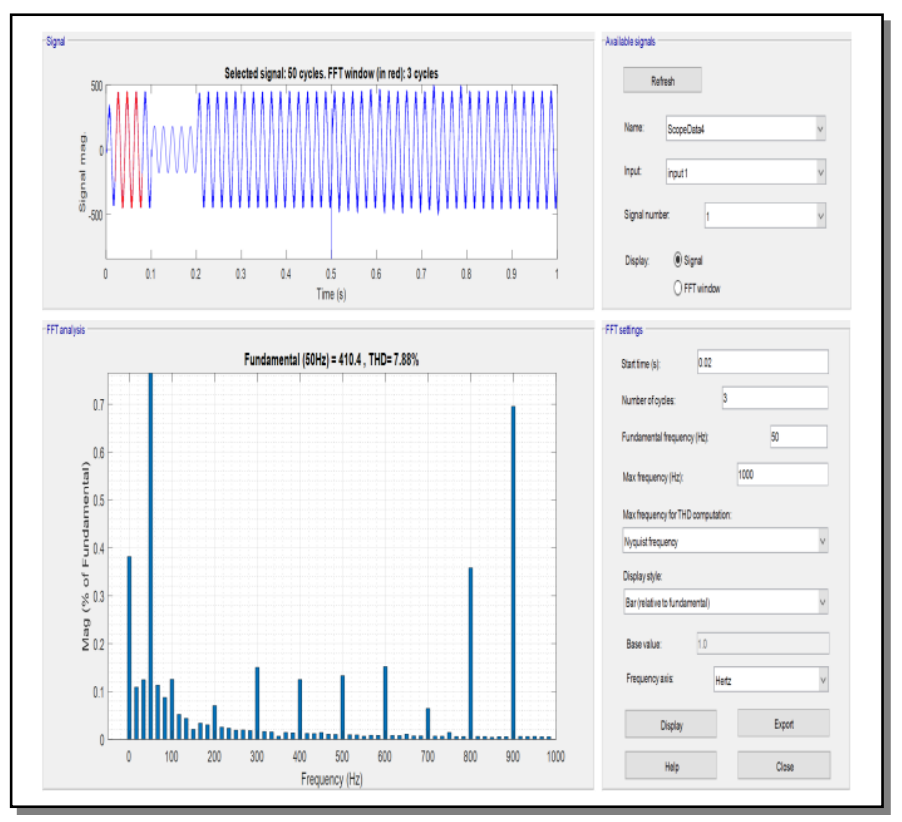

Fig..10 FFT Analysis Carried On Load Voltage Without DVR.

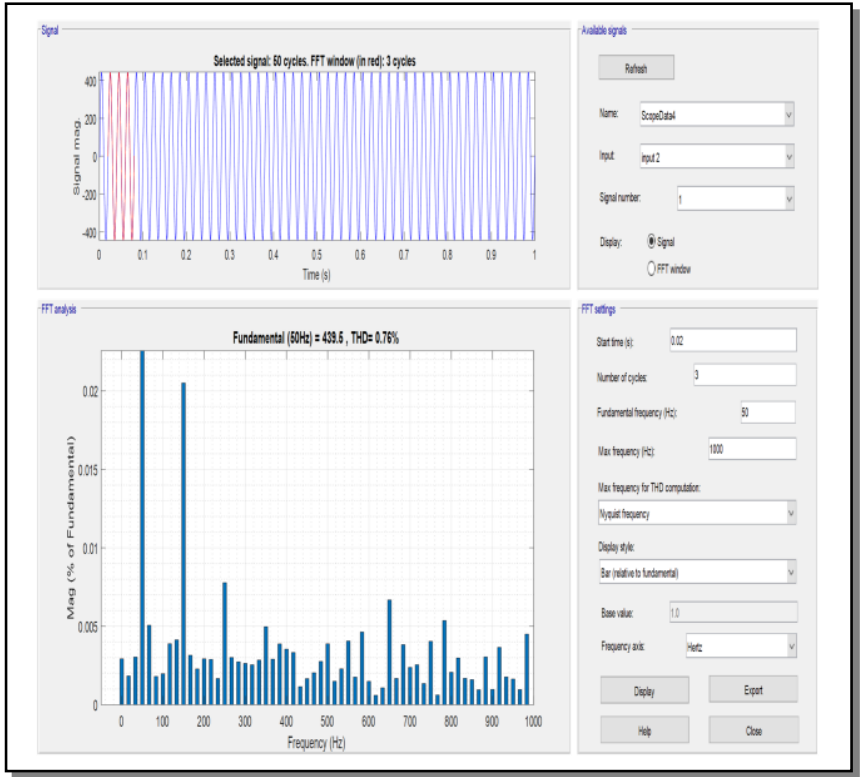

Fig.11 FFT Analysis Carried On Load Voltage With DVR.

The FFT analysis is carried on the output load voltage for 3 cycles with DVR and without DVR control and the results obtained for both the conditions can be observed in Fig.10 and in Fig. 11 respectively. From the results it is evident that there is significant reduction in the THD when DVR control is used. The THD is reduced from $7.888 \%$ to $0.76 \%$ which is below $5 \%$ as per the IEEE standards.

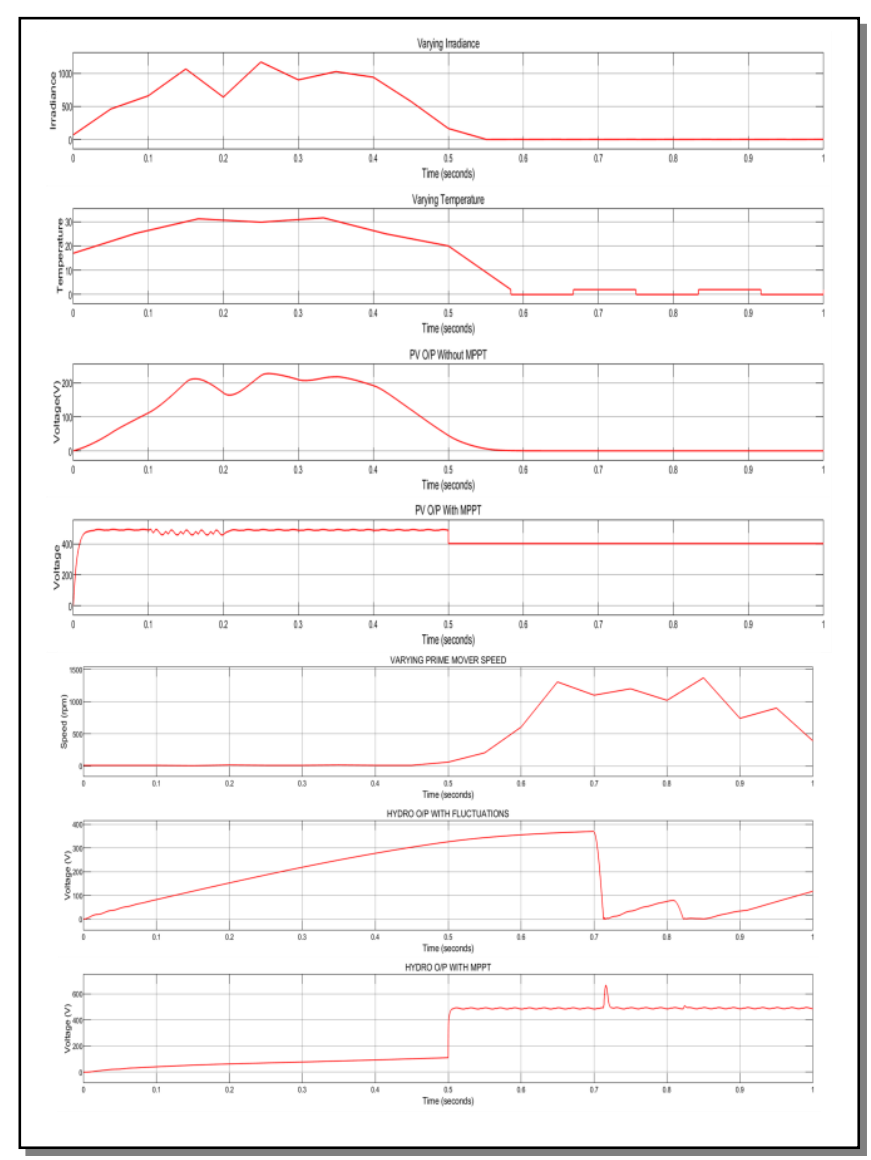

Fig.12 Overall Results Demonstrating the Performance Of MPPT Control Scheme and Power Quality Compensation Scheme. 


\section{CONCLUSION}

The hybrid model designed mainly focuses on the output optimization and power quality retention. The system designed is capable of maintaining its power at maximum level irrespective of the environmental changes. The pv system operates at maximum power point even though there are fluctuations in temperature and irradiation levels also; the hydro system produces maximum power despite the varying prime speed. Incorporation of the incremental conductance algorithm of maximum power point tracking is used. The output characteristics of the hybrid hydro/pv system are simulated considering the shading effect, varying temperature and speed. Sepic converter is used to boost the tracked voltage and thus along with mppt control its helps in maintaining a constant voltage. The output of chb inverter is stepped down to $440 \mathrm{v}$ ac. The disturbances to the power quality caused by the faults leading to voltage sags are addressed by a power quality compensation scheme. The dvr control used in the model is capable of maintaining the desired voltage profile of the system thus helps in controlling the power quality of the system. The harmonics distortions present in the load voltage waveforms were observed using fft analysis tool in matlab/simulink. The total harmonic distortion is reduced to $0.76 \%$ from $7.88 \%$ with the incorporation of dvr. The functionality of the entire proposed model has been demonstrated by simulation, and the results obtained are found to be satisfactory.

\section{REFERENCES}

[1] Sweeka Meshram, Ganga Agnihotri and Sushma Gupta "MODELING OF GRID CONNECTED DC LINKEDPV/HYDRO HYBRID SYSTEM," Electrical and Electronics Engineering: An International Journal (ELELIJ) Vol 2, No 3, August 2013.

[2] Lakhdar Belhadji, Seddik Bacha, Iulian Munteanu, Axel Rumeau, Daniel Roye, "Adaptive MPPT Applied to Variable-Speed Microhydropower Plant," IEEE Transactions on Energy Conversion ( Volume: 28 , Issue:1, March 2013 )

[3] Dogga Raveendhra, M K Pathak, "Modular Multi Level Inverter with Self-Healing Power Unbalancing Capability in Single Stage Solar PV
Systems," 2017 IEEE 15th Student Conference on Research and Development (SCOReD).

[4] P Rakshith, Jahnavi R bhat, M Ashwini, C R Rakshitha, Vinay kumar sharma. "Output Maximization by Modeling and Simulation of Hybrid Wind/Photovoltaic Standalone Generation", 2017 International Conference on Current Trends in Computer, Electrical, Electronics and Communication (CTCEEC), 2017

[5] Trishan Esram, Student Member, IEEE, and Patrick L. Chapman, Senior Member, IEEE, "Comparison of Photovoltaic Array Maximum Power Point Tracking Techniques," in IEEE Photovoltaic Spec. Conf. 1980, pp. 523-527

[6] Falin, Jeff. "Designing DC/DC converters based on SEPIC topology" 2008, Texas Instruments. December 2013

[7] B. P. McGrath and D. G. Holmes, "Multicarrier PWM strategies for multilevel inverters," IEEE Trans. Ind. Electron., vol. 49, no. 4, pp. 858-867, Aug. 2002.

[8] D. Y. Dasin*, N. Y. Godi, O. C. Kingsley Experimental, "Investigations of the Performance of Passive Solar Food Dryer" International Journal of Energy Engineering 2015.

[9] A. K. Katiyar, C. K. Pandey, "Correlation for estimation of hourly solar radiation," International journal of energy and environment Volume 2, Issue 1, 2011 pp.191-198.

[10] Sanu Thomas P, Arun Xavier, "Cascaded H Bridge Fifteen Level Inverter," International Journal of Energy Engineering 2015, 5(1): 9 15DOI: $10.5923 /$ j.ijee.20150501.03

[11] T. Salmi, M. Bouzguenda, A. Gagtli, "MATLAB/Simulink based modeling of solar photovoltaic cell," International journal of renewable energy research, vol.2, no. $2,2012$.

[12] E. Babaei , M. Farhadi Kangarlu, "Voltage quality improvement by a dynamic voltage restorer based on a direct three-phase converter with fictitious DC link," IET Generator Transmission Distribution, vol. 5, Iss. 8, pp. 814-823, 2011.

[13] P. Ananthababu, B. Trinadha and K. Ram charan, "Performance of Dynamic Voltage Restorer (DVR) against Voltage sags and swells using Space Vector PWM Technique," International Conference on Advances in Computing, Control, and Telecommunication Technologies, 2009.

[14] Falin, Jeff. "Designing DC/DC converters based on SEPIC topology" 2008, Texas Instruments. December 2013 http://www.ti.com/lit/an/snva168e/snva168e.pdf 